\title{
PRINCIPAIS MANIFESTAÇÕES PATOLÓGICAS NAS FACHADAS DE EDIFÍCIOS DO BAIRRO ASA SUL, BRASÍLIA-DF
}

\author{
CAVALCANTE, CAROLINNE LISBOA \\ Engenheira Civil \\ Centro Universitário do Distrito Federal - UDF \\ Distrito Federeal; Brasil \\ carolinnelisboacavalcante@ hotmail.com
}

\author{
CHATER, LATIF \\ Engenheiro Civil \\ JR \& Chater \\ Distrito Federal; Brasil \\ jrchater@gmail.com
}

\author{
SILVA, JULIANO RODRIGUES \\ Docente de Engenharia Civil \\ Universidade Estadual de Goiás \\ Goiás; Brasil \\ julianorodriguessilva@gmail.com \\ SCHMIDT, ANDREIA \\ Engenheira Civil \\ Universidade Fernando Pessoa \\ Porto, Portugal \\ eng.andreiaschmidt@gmail.com
}

\begin{abstract}
RESUMO
$\mathrm{O}$ trabalho apresenta as principais manifestações patológicas nas fachadas de edifícios residenciais no bairro Asa Sul, que é um bairro da região administrativa de Brasília, no Distrito Federal, sendo uma área tombada pela UNESCO (Organização das Nações Unidas para a Educação, a Ciência e a Cultura). Foram encontradas fissuras com manchas escuras, descascamento de pintura sobre pastilhas, manchas de escorrimento de água sobre pintura, fissuras na pintura das pastilhas da fachada e desplacamento de reboco construtivo. A partir de informações obtidas através de vistorias nas diversas edificações, as fachadas foram analisadas de acordo com norma de Inspeção Predial Nacional do IBAPE (Instituto Brasileiro de Avaliações e Perícias de Engenharia) de 2012, com o objetivo de ser utilizada como referência, para as manutenções preditivas necessárias à extensão da vida útil dos edifícios. Todas as fachadas analisadas foram de edifícios com sistema estrutural e construtivo semelhantes, bem como a finalidade de uso da edificação, todos residenciais. A inspeção predial foi baseada na vistoria visual da edificação, que tem como resultado a análise técnica do fato ou da condição relativa à utilização, mediante a verificação "in loco", para cada manifestação patológica apontada foram apresentados registros fotográficos, assim como as sugestões para a solução dessas referidas patologias. As anomalias e falhas foram classificadas em três diferentes graus de recuperação (mínimo, regular e crítico), considerando o impacto do risco oferecido aos usuários, ao meio ambiente e ao patrimônio.
\end{abstract}

Palavras-chave: fachada, manifestações patológicas, edifícios.

\section{ABSTRACT}

The paper presents the main pathological manifestations on the facades of residential buildings in the Asa Sul neighborhood, which is a neighborhood of the administrative region of Brasilia, in the Distrito Federal, being an area listed by UNESCO (United Nations Educational, Scientific and Cultural Organization). Were found cracks with dark spots peeling paint on tablets, water dripping on paint, cracks in the paint of the facade tablets and detachment of constructive plaster. From information obtained through surveys in the various buildings, the facades were analyzed according to the National Building Inspection standard of IBAPE (Brazilian Institute of Engineering Appraisals and Assessments) of 2012, in order to be used as a reference for the predictive maintenance required to extend the life of buildings. All facades analyzed were of buildings with similar structural and constructive system, as well as the purpose of use of the building, all residential. The building inspection was based on the visual inspection of the building, which results in the technical analysis of the fact or condition related to the use, by means of on-site verification. Photographic records were presented for each pathological manifestation indicated, as well as suggestions for the solution of these pathologies. Anomalies and failures were classified into three different degrees of recovery (minimum, regular and critical), considering the impact of the risk offered to users, the environment and patrimony.

Keywords: facade, pathological manifestations, buildings. 


\section{INTRODUÇÃO}

As fachadas correspondem a cada uma das faces de qualquer edificação. E, assim como qualquer outro elemento de um edifício, podem apresentar manifestações patológicas decorrentes de intempéries como sol e chuva, considerando que sua integridade interfere no desempenho de outros elementos que fazem parte da construção, analisar as manifestações patológicas nesse elemento é fundamental.

Diante da certeza da interferência de fatores externos, como variação de temperatura, chuvas, sol, ventos, deformações mecânicas, nas fachadas, torna-se inquestionável que um bom estudo, planejamento e desenvolvimento de um projeto executivo de fachada, minimiza o surgimento de patologias, aumentando a vida útil dos revestimentos das fachadas.

As origens mais comuns que culminam no surgimento de problemas nesses elementos são provenientes de projeto que pode ter sido mal elaborado ou, embora tenha seguido âs normas e especificações técnicas, possa ter sido mal executado (concepção da edificação), dos materiais utilizados (muitas vezes, em desacordo com as normas vigentes), e do uso da edificação (relacionado às manutenções necessárias para o bom desempenho da construção).

De acordo com Souza e Ripper (1998), é chamada de patologia das estruturas, a área da engenharia civil que se ocupa do estudo das origens, formas de manifestação, consequências e mecanismos de ocorrência das falhas e dos sistemas de degradação das estruturas. É uma área que vai além da identificação e conhecimento das anomalias, se relaciona, também, à concepção e ao projeto das estruturas, e se estende, até mesmo, à formação do engenheiro civil. Para Helene (1992), a patologia das construções pode ser definida como sendo um ramo da engenharia que estuda desde a origem dos defeitos até o diagnóstico e o tratamento do problema.

Considerando que, mesmo estruturas bem projetadas e construídas apresentam sintomas patológicos devido ao desgaste natural da estrutura, as análises patólógicas são indispensáveis para assegurar um desempenho satisfatório ao longo da vida útil da construção. A fim de se obter sucesso, no que diz respeito, às soluções para os problemas patológicos diagnosticados é necessário que o diagnóstico tenha sido bem feito, que se conheça muito bem as vantagens e desvantagens de cada material, e para cada situação particular a melhor alternativa de solução.

Com o objetivo de minimizar o surgimento de patologias construtivas e auxiliar os profissionais desse setor, foram criadas normas técnicas sobre desempenho das edificações, manutenções, perícias e inspeções, com diretrizes e recomendações que devem ser seguidas com o propósito de manter o desempenho esperado das edificações. No Brasil, devido ao crescente número de incidentes envolvendo os estados de conservação das estruturas, notou-se a necessidade de melhorar as perícias técnicas, os laudos técnicos de inspeção predial e de conscientizar a população sobre a importância desse serviço para manter a segurança, o uso e ocupação dessas edificações.

A falta de manutenção das fachadas possui impacto, principalmente, na parte visual (estética) da edificação, levando o imóvel à desvalorização devido aos problemas aparentes. Além de representar um grande risco aos transeuntes que circulam próximo às edificações com desplacamento de revestimentos e rebocos.

Dessa forma, este artigo tem a intenção de analisar a conservação e vida útil das fachadas de edifícios residenciais no bairro Asa Sul, Brasília-DF, bem como, a identificação de anomalias e de falhas que se apresentam de forma aparente. Para cada manifestação patológica apontada nas fachadas foram apresentados registros fotográficos, assim como as sugestões para a solução dessas referidas patologias.

\section{METODOLOGIA}

As inspeções prediais foram baseadas na vistoria visual das edificações, que tem como resultado a análise técnica do fato ou da condição relativa à utilização, mediante a verificação "in loco" de cada sistema construtivo, no que tange a segurança e a manutenção predial, que foram pautadas de acordo com as diretrizes da Norma de Inspeção Predial do IBAPE (Instituto Brasileiro de Avaliações e Perícias de Engenharia) - 2012, no seu Nível de Inspeção 01 e as especificações da Norma de Manutenção em Edificações - NBR 5674 (1999), da ABNT.

A inspeção procede ao diagnóstico das anomalias construtivas e falhas de manutenção que interferem e prejudicam o estado de utilização do prédio e suas instalações, tendo como objetivo verificar os aspectos de desempenho, vida útil, utilização e segurança que tenham interface direta com os usuários. As normas de inspeção do IBAPE, estabelece três 
níveis quanto a complexidade e elaboração de laudo, consideradas as características técnicas da edificação, manutenção e operação existentes e necessidade de formação de equipe multidisciplinar para execução dos trabalhos:

Nível 1: a inspeção deve ser elaborada por profissional habilitado em uma especialidade, considerando-se uma edificação com baixa complexidade técnica, de manutenção e operação de seus elementos e sistemas construtivos.

Nível 2: a inspeção deve ser elaborada por profissional habilitado em uma ou mais especialidades, considerando-se uma edificação com média complexidade técnica, de manutenção e operação de seus elementos e sistemas construtivos;

Nível 3: é elaborada por profissionais habilitados e de mais de uma especialidade, nesse caso, o trabalho pode ser intitulado como auditoria técnica, considerando seu alto grau de complexidade técnica, de manutenção e operação.

A inspeção realizada neste trabalho, é classificada como “Inspeção de Nível 01”, representada por análise expedita dos fatos e sistemas construtivos vistoriados, com a identificação de suas anomalias e de falhas que se apresentam de forma aparente.

Caracteriza-se pela verificação isolada ou combinada das condições técnicas de uso e de manutenção do sistema da edificação, de acordo com a Norma de Inspeção Predial do IBAPE (2012), respeitado o nível de inspeção adotado, com a classificação das deficiências encontradas quanto ao grau de risco que representa em relação à segurança dos usuários, à habitabilidade e à conservação do patrimônio edificado.

Conforme a referida Norma de Inspeção Predial do IBAPE (2012), as anomalias e falhas são classificadas em três diferentes graus de recuperação (mínimo, regular e crítico), considerando o impacto do risco oferecido aos usuários, ao meio ambiente e ao patrimônio:

Grau de risco mínimo $(\mathbf{M})$ - Risco de causar pequenos prejuízos à estética ou atividade programável e planejada, sem incidência ou sem a probabilidade de ocorrência dos riscos críticos e regulares, além de baixo ou nenhum comprometimento do valor imobiliário a edificação.

Grau de risco regular $(\mathbf{R})$ - Risco de provocar a perda parcial de desempenho e funcionalidade da edificação sem prejuízo à operação direta de sistemas, e deterioração precoce do edifício.

Grau de risco crítico (C) - Risco de provocar danos contra a saúde e segurança das pessoas e do meio ambiente; perda excessiva de desempenho e funcionalidade causando possíveis paralisações; aumento excessivo de custo de manutenção e recuperação; comprometimento sensível de vida útil da edificação.

\section{MANIFESTAÇÕES PATOLÓGICAS}

\subsection{Fissuras na fachada}

Nesse caso, as fissuras apresentam manchas escuras em suas bordas. Essas manchas são decorrentes da umidade e são causadas pela ascensão da água até a superfície, pode acontecer devido a capilaridade (propriedade físicca da água) ou por fenômenos externos. Essa água, pode ainda, atingir uma das armaduras da estrutura e estimular o surgimento de corrosão e outras manifestações patológicas.

Manifestações patológicas: Ocorrem fissuras no topo do edifício dessa fachada (Figura 1), e essas fissuras apresentam manchas escuras em suas bordas. Ocorre, também, uma fissura próxima a estrutura em balanço (parte da estrutura que se projeta para além da última fileira de pilares) dos pilotis, como é possível observar na Figura 2.

Classificação do Problema: Anomalia construtiva; 


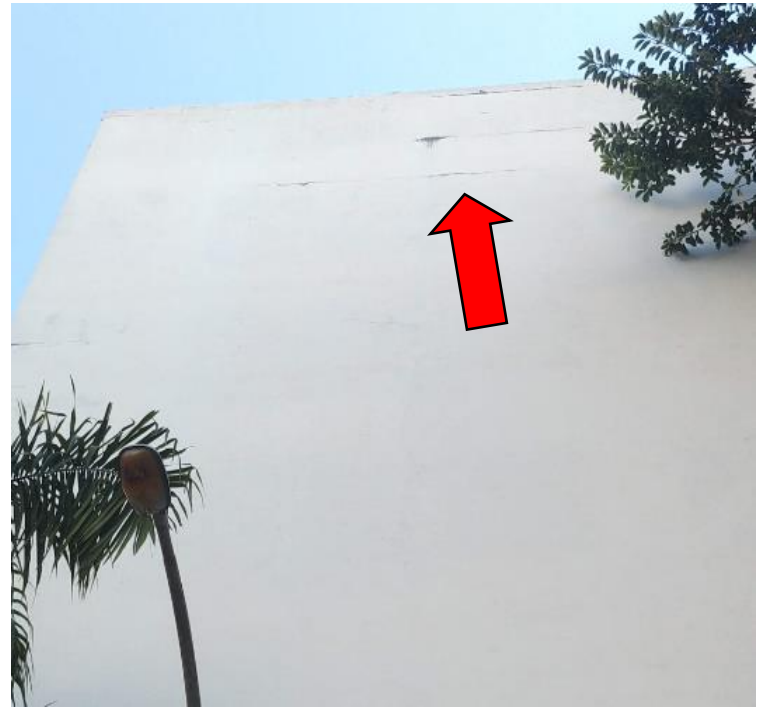

Figura 1: Fissuras e manchas no topo do edifício

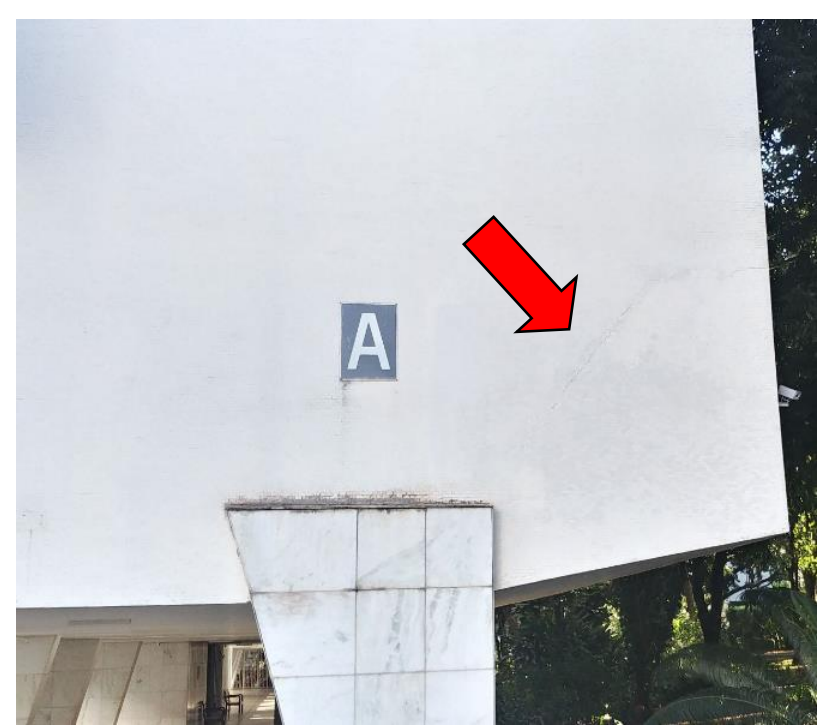

Figura 2: Fissuras e manchas no balanço do edifício

Possíveis Causas: De acordo com Thomaz (2007): “As platibandas, em função da forma geralmente alongada, tendem a comportar-se como os próprios muros de divisa; normalmente surgirão fissuras verticais regularmente espaçadas, caso não tenham sido convenientemente projetadas juntas ao longo da fachada. As movimentações térmicas diferenciadas entre a platibanda (mureta que esconde os telhados acima da última laje) e o corpo do edifício poderão resultar ainda no desplacamento da platibanda e na formação de fissuras inclinadas nas extremidades desse corpo, conforme o ilustrado na Figura abaixo" (Figura 3).

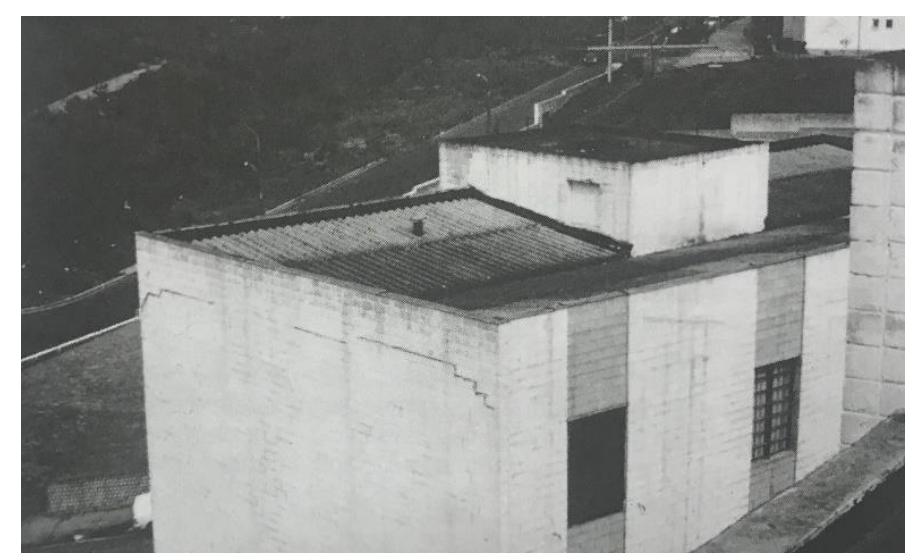

Figura 3: Fissuras e manchas no topo do edifício

A fissura mostrada na Figura 2 diz respeito a outro fenômeno. Provavelmente se deve a uma pequena movimentação estrutural do edifício naquele ponto, pela tendência de a viga e a laje de rotacionarem em torno do pilar abaixo, o que gera uma tensão de separação da parte mais próxima a fachada adjacente do apartamento em relação a parte mais central. Este movimento de rotação se deve ao sistema de apoio naquele local, que está em balanço (quando uma parte da estrutura se projeta para além da última fileira de pilares). A fissura sinaliza que a estrutura pode estar sendo solicitada além da sua capacidade resistente. As Figuras 4 e 5 ilustram o movimento que ocorre nas vigas em balanço da estrutura.

Intervenção: : Para a fissura horizontal próxima a platibanda sugere-se a criação de uma junta de movimentação ao longo do encontro da platibanda com a estrutura de concreto armado, que coincide, provavelmente com o local de surgimento da fissura. Esta junta possibilitará a dilatação térmica sem surgimento de fissuras, embora há também pequena possibilidade de surgimento de fissuras, especialmente nas extremidades. Recomenda-se, ainda, acompanhar a abertura da fissura de $45^{\circ}$ na parte mais baixa da fachada com selos de gesso, fora do período de chuvas, que podem ser aplicados com pasta de gesso em formato retangular (aproximadamente $2 \mathrm{~cm}$ de largura e $4 \mathrm{~cm}$ de comprimento) sobre as fissuras a serem monitoradas, perpendicularmente ao sentido dessa fissura. O gesso é um material rígido, extremamente sensível ao esforço de tração. Assim, se a fissura se abrir, o selo logo será puxado pelos dois lados da fissura (sofrendo esforço de tração) e se 
romperá antes do concreto da laje, que possui maior resistência. Nos primeiros três meses, recomenda-se verificar a integridade dos selos a cada 15 dias. Caso haja rompimento dos selos, há sinalização de que a estrutura continua trabalhando e poderá ser necessária uma intervenção na estrutura, através de projeto de recuperação estrutural.

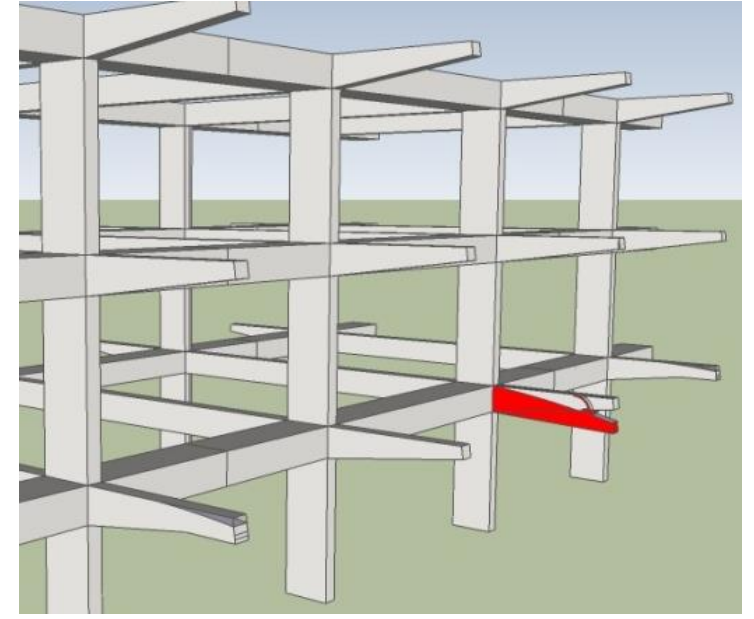

Figura 4: Fissuras na fachada (adaptado de Chater)

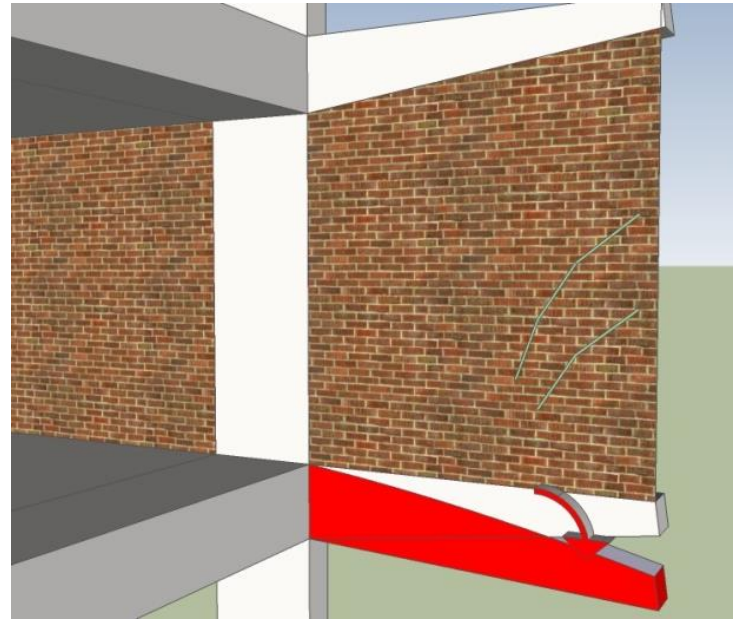

Figura 5: Fissura na fachada - aproximado (adaptado de Chater)

Risco: R (Grau Regular)

Observação: Caso ocorra a exposição da armadura (ferragem) em quaisquer apartamentos deve-se proceder a análise do grau de oxidação (ferrugem) em que ocorre a deterioração da peça estrutural, pois esse ponto é sensível a colapsos, se a região da armadura não estiver integralmente protegida pelo concreto.

Como a avaliação estrutural é realizada na área comum do prédio faz-se necessário que cada condômino alerte se a sacada ou qualquer outro ambiente do apartamento apresentam fissuras, rachaduras e (ou) exposição de armadura (ferragem do concreto exposta). O inquilino deve imediatamente avisar ao síndico ou o preposto, o fato, para as providências necessárias com profissional qualificado, essa situação apresenta risco de colapso progressivo, dependendo do grau de dano das sacadas, se não for sanada de forma satisfatória.

\subsection{Descascamento de pintura sobre pastilhas}

Manifestações patológicas: : Foram observados descascamento da pintura sobre as pastilhas na parte baixa das fachadas.

Classificação do Problema: Anomalia construtiva;

Possíveis Causas: Dentre as possíveis causas, destacam-se a especificação equivocada de material de pintura para revestimento cerâmico e o desgaste natural do material pelo tempo e incidência de intempéries. Os revestimentos cerâmicos possuem superfície lisa, que dificultam a aderência de pinturas, não sendo aconselhável este procedimento, especialmente em áreas sujeitas a sol e chuva.

Intervenção: Recomenda-se, caso se deseje manter a pintura naquela parte da fachada, remover as pastilhas antigas, regularizar a superfície, deixando-a rugosa, com aplicação de argamassa de reboco e (ou) pintando-a com pintura texturizada lavável e adequada para exposição ao tempo.

Risco: M (Grau Mínimo). 


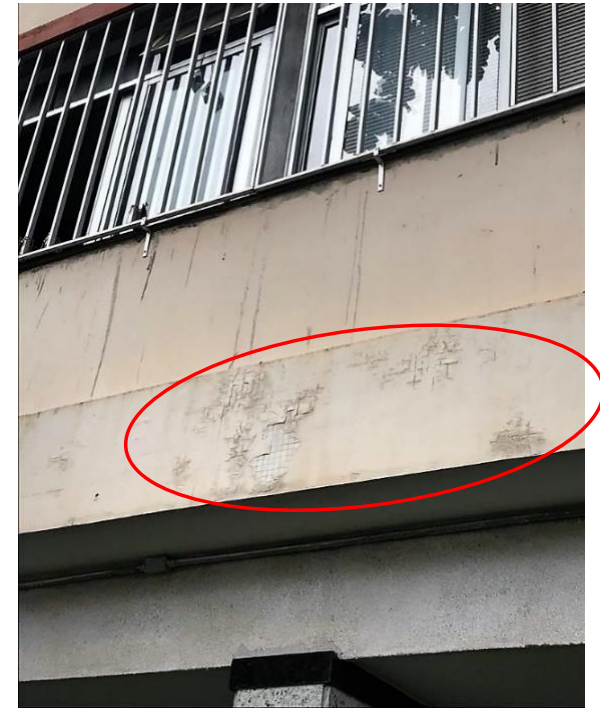

Figura 6: Descascamento da pintura na fachada

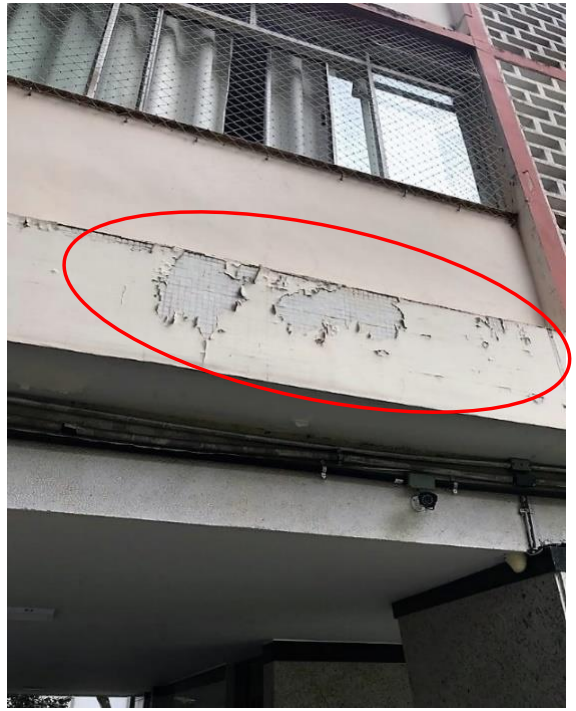

Figura 7: Descascamento da pintura na fachada

\subsection{Manchas de escorrimento de água sobre pintura}

Manifestações patológicas: : Foram observadas manchas de escorrimento de água sobre a pintura e o descascamento de pintura nas faces externas de varandas (floreira).

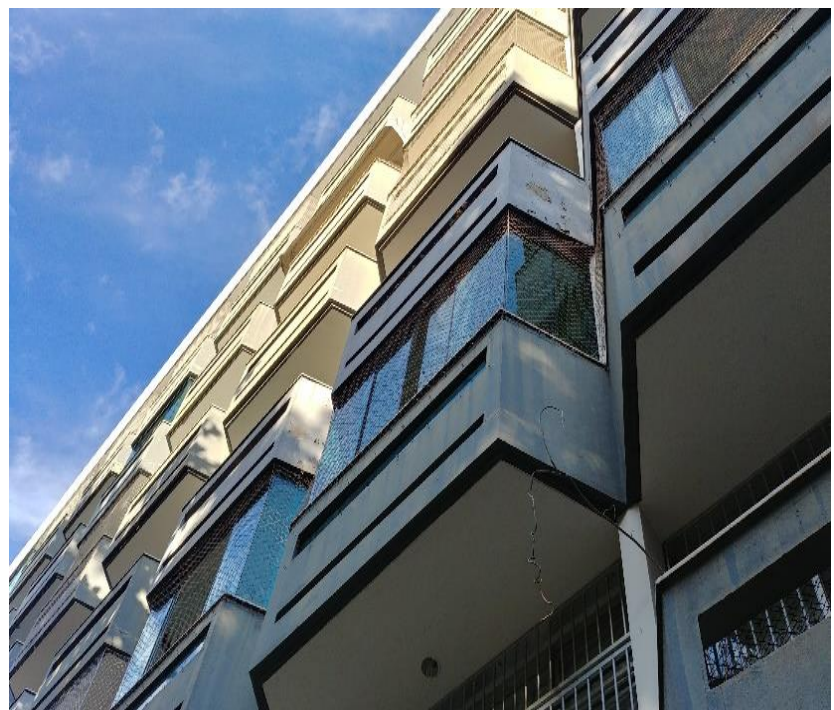

Figura 8: Varanda (floreira)

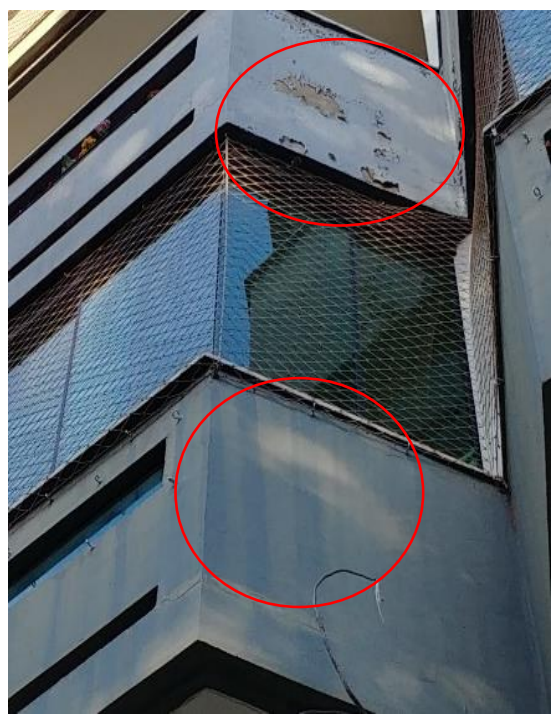

Figura 9: Detalhe da varanda mostrando o descascamento de pintura (círculo de cima) e manchas de escorrimento na pintura (círculo de baixo)

Classificação do Problema: Anomalia construtiva;

Possíveis Causas: Aponta-se como principal causa possível das manchas e descascamento de pintura mencionados o mau funcionamento das pingadeiras, que são neste caso as placas de granito sobre o guarda-corpo de alvenaria. Estas servem ao propósito de receber a água da chuva e desviá-la para que não adentre a alvenaria, o que causaria infiltrações e para que não escorra pela parede, pingando a alguma distância dela. As pingadeiras podem estar curtas demais no sentido transversal (no sentido das abas que se destacam da parede abaixo) e (ou) sem friso na parte debaixo da aba (vide Figura 10) para o procedimento correto de instalação de pingadeiras. 
O processo de degradação das pinturas nestes casos é lento e tem relação também com a qualidade da pintura executada, tanto pelo material quanto pela mão de obra de execução.

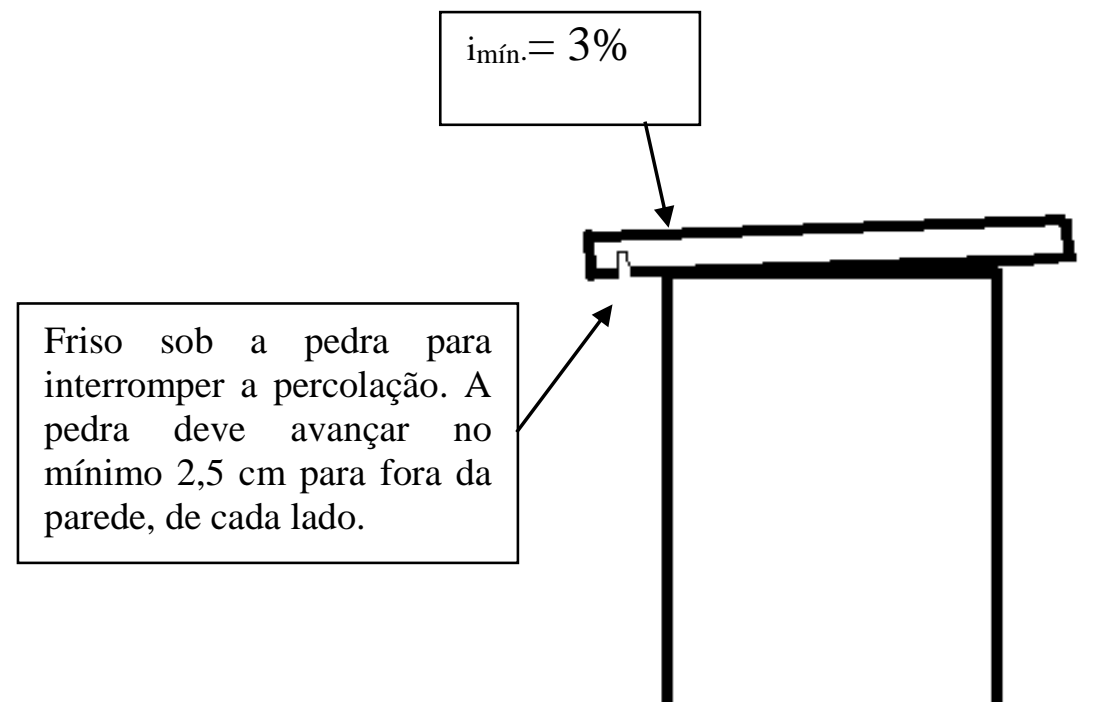

Figura 10: Detalhe construtivo de pingadeira de granito (corte)

Intervenção: A manifestação patológica provoca incômodo principalmente do ponto de vista estético. Como intervenção, deve-se refazer as pingadeiras obedecendo os critérios técnicos da boa prática da engenharia, como ilustra a Figura 10, e posteriormente pintar novamente a fachada. Com as pingadeiras funcionando de maneira correta, as pinturas vão se manter em bom estado por mais tempo, sem a ocorrência de manchas provenientes de infiltrações.

Risco: M (Grau Mínimo).

\subsection{Fissuras devido à falta de juntas de movimentação nas pastilhas}

Manifestações patológicas: Foram observadas fissuras na pintura das pastilhas nas partes baixas da Fachada, abaixo dos Cobogós.

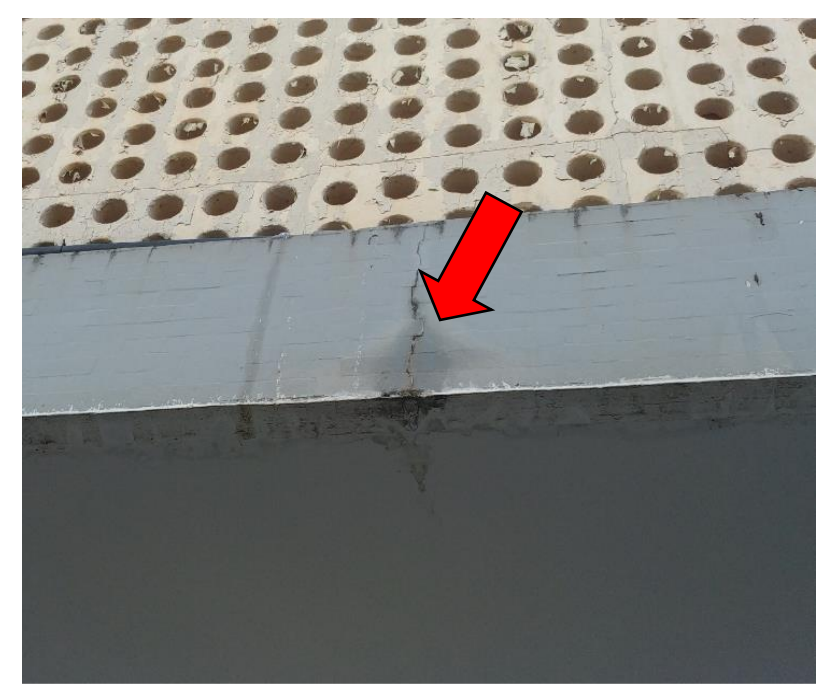

Figura 11: Fissuras na pintura da fachada

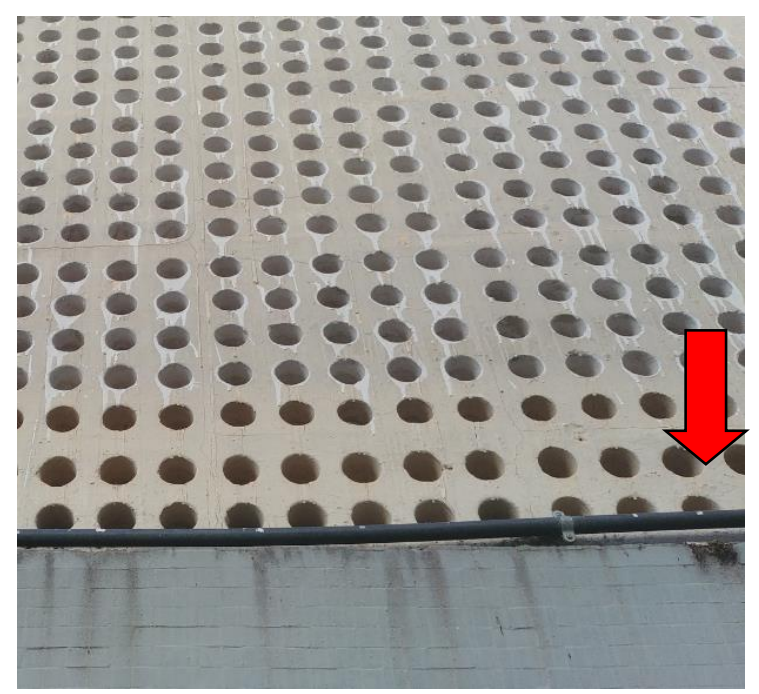

Figura 12: Fissuras na pintura da fachada

Classificação do Problema: Falha na manutenção e anomalia construtiva; 
Possíveis Causas: A extensão da faixa com pastilha abaixo do Cobogó que apresenta a manifestação patológica é extensa no sentido horizontal entre juntas. As pastilhas, quando instaladas em fachadas, especialmente, estão sujeitas as ações do tempo (sol e chuva), com dilatação durante o dia e retração a noite. Em função disso, estes "panos" de pastilhas necessitam de juntas de movimentação. Estas são distintas das juntas de dilatação estruturais do prédio e servem para o sistema de revestimento (emboço ou reboco e pastilhas). A Figura 11 ilustra esta junta.

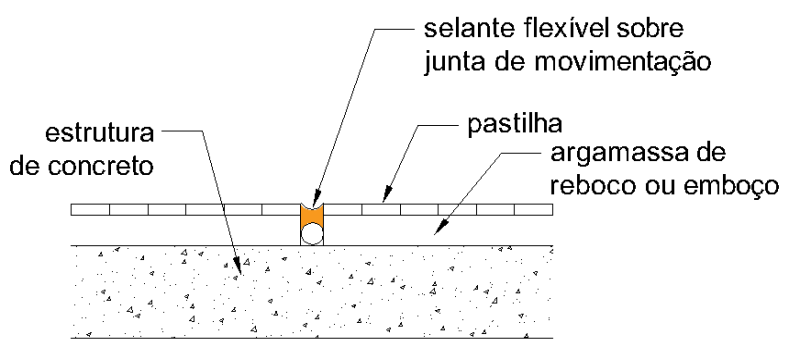

Figura 13: Detalhe da junta de movimentação para sistema de revestimento de fachada com pastilhas (JR \& Chater,

2019).

Intervenção: Sugere-se a criação de juntas de movimentação do tipo ilustrado na Figura 13 a cada 5 metros de distância de uma junta a outra, no mínimo, para prevenir o ressurgimento das fissuras.

Risco: M (Grau Mínimo).

\subsection{Desplacamento do revestimento argamassado}

Manifestações patológicas: Foi observado desplacamento de reboco de alguns pontos específicos das fachadas, especialmente nos ressaltos pintados de vermelho que fazem quadro em torno das esquadrias.

Classificação do Problema: Anomalia construtiva;

Possíveis Causas: É possível que a argamassa aplicada tenha sido feita com traço inadequado, ou seja, proporções de cimento, areia, água e aditivos (cal, aditivos plastificantes, etc.) inadequadas. Outra possibilidade é que a argamassa, no momento da execução da obra, tenha sido deixada misturada por tempo demais, ou seja, o "tempo em aberto" do material teria sido desrespeitado, causando a pega do cimento de forma precoce, antes da aplicação na fachada, o que prejudicaria a sua aderência.

Uma terceira possibilidade seria que a base sobre a qual a argamassa foi aplicada estava mal preparada, seja por não estar rugosa o suficiente, ou por falta de umidade por não ter sido molhada antes da aplicação do reboco, o que prejudicaria a aderência da argamassa de reboco, uma vez que a rugosidade do substrato (base) e a sua umidade são fatores preponderantes na aderência da argamassa aplicada.

Um agravante para qualquer das hipóteses acima é o desgaste natural com o transcorrer do tempo, devido à ação constante do sol e da chuva, que provocam a dilatação do material, com o seu aquecimento ou encharcamento e retração com o resfriamento ou secagem. A falta de um sistema de pingadeira sobre a superfície horizontal também favorece a ação da água sobre o sistema de revestimento.

Intervenção: Bem como para todas as intervenções prescritas neste artigo, recomenda-se contratar empresa especializada, com acompanhamento de profissional da engenharia ou arquitetura, qualificados para realizar as intervenções necessárias para cada tipo de manifestação patológica. Nesse caso, é preciso realizar um ensaio de percussão, esse ensaio é utilizado com o objetivo de identificar as regiões que apresentam problemas de aderência, e consiste no procedimento descrito abaixo:

1. Identificar pontos "fofos", que estejam no limiar de se soltar;

2. Remover a argamassa de revestimento nestes pontos; 
3. Preparar a superfície, limpando-a, primeiramente, depois aplicando chapisco, seguido por emboço e reboco (ou reboco paulista, aplicado em uma camada simples). Observar o caimento pronunciado para fora do ressalto, na superfície superior horizontal, com algum tipo de sistema de pingadeira, para evitar acúmulo indesejado de água;

4. Pintar a superfície juntamente com o restante não tratado para eliminar possíveis diferenças de tonalidade na cor (opcionalmente pode-se aplicar massa acrílica antes da pintura, embora isto não seja recomendado em superfícies horizontais);

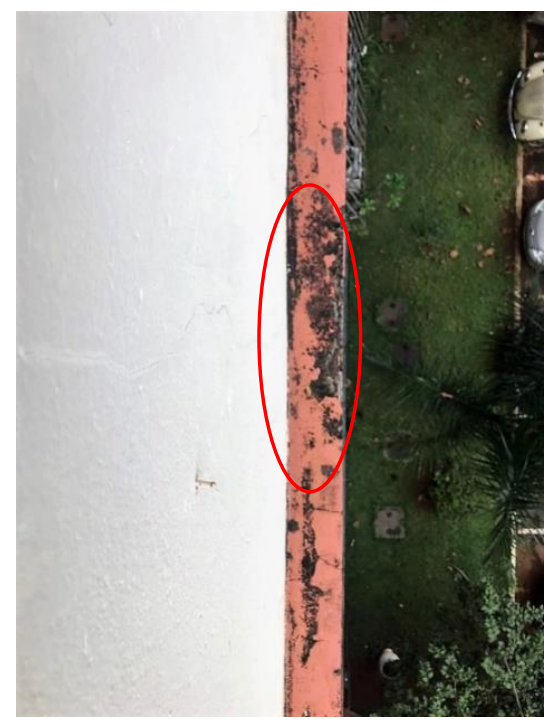

Figura 14: Desplacamento de reboco do ressalto em vermelho da fachada

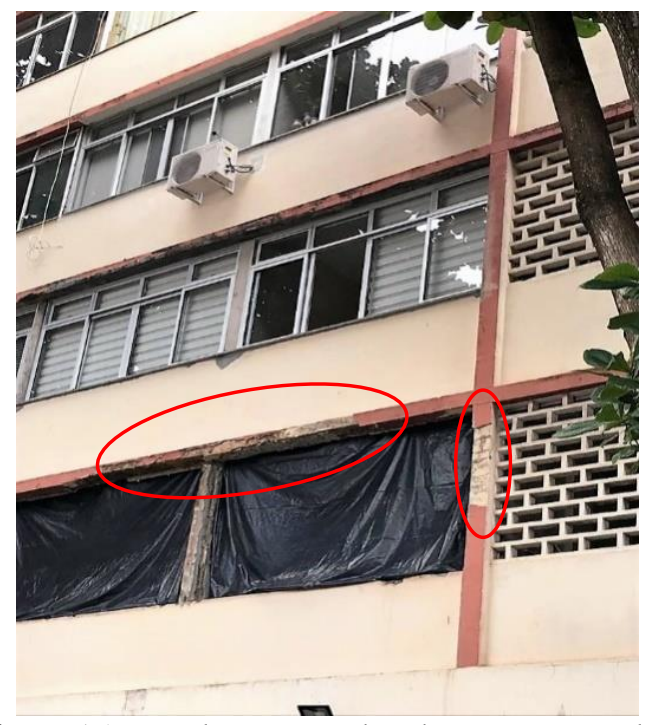

Figura 15: Desplacamento de reboco em vermelho - vista frontal da fachada

Deve-se atentar para as manutenções periódicas da fachada especialmente em virtude da possibilidade de queda de materiais sobre transeuntes e (ou) os próprios condôminos

Risco: C (Grau Crítico).

\section{CONCLUSÃO}

É possível observar que a maioria das fachadas, com as manifestações patológicas retratadas nesse artigo, são de prédios antigos. A causa principal dessas falhas é decorrente da falta de manutenção adequada e dentro dos parâmetros exigidos pelas normas vigentes no país. Ressalta-se que para a elaboração de um bom projeto executivo de fachada, é necessário ater-se às especificações de projeto, à aquisição, controle e armazenamento dos materiais utilizados, ao preparo adequado da base do revestimento da fachada, à produção e aplicação adequada da argamassa de revestimetos, ao controle tecnológico, ao treinamento da mão-de-obra e à atenção constante do engenherio responsável pela obra que está sendo executada.

Dentre os itens inspecionados, os que exigem maior atenção está os desplacamentos do revestimento argamassado da fachada, que pode resultar em infiltrações no interior dos apartamentos, e oferecer maior risco aos transeuntes à edificação, visto o risco de queda desse reboco em cima de uma pessoa.

No âmbito geral, pode-se dizer que os demais problemas surgem em virtude dos edifícios serem antigos, além de terem sofrido diversas intervenções ao longo de sua história, resultando em anomalias construtivas. Muitos de seus elementos construtivos se encontram, portanto, em situações suscetíveis à apresentação de manifestações patológicas, pois estão se deteriorando naturalmente.

As manutenções preventivas são fundamentais para a extensão da vida útil da edificação como um todo, fundamentadas em monitoramentos periódicos ao longo de sua vida útil. As sugestões de intervenções estruturais mencionadas neste trabalho são de caráter corretivo e preventivo, e buscam garantir a segurança dos condôminos e demais usuários. 
Com o objetivo de manter a qualidade, a segurança e o desempenho das edificações, é indispensável a realização de pesquisas na área das patologias construtivas, suas causas e soluções, com o intuito de fornecer instruções e assistência aos profissionais atuantes nessa área da construção civil, para que não apenas os elementos das fachadas, mas todos os elementos que compõem as edificações, estejam sempre dentro das normas de desempenho e segurança previstas no Brasil.

\section{AGRADECIMENTOS}

Agradecemos a empresa JR \& Chater Engenharia por disponibilizar e auxiliar na elaboração desta pesquisa.

\section{REFERÊNCIAS}

ASSOCIAÇÃO BRASILEIRA DE NORMAS TÉCNICAS. NBR 9575: Impermeabilização - Seleção e Projeto. Rio de Janeiro, 2010.

ASSOCIAÇÃO BRASILEIRA DE NORMAS TÉCNICAS ABNT: NBR $\mathbf{5 6 7 4}$ Manutenção de edificaçõesprocedimento, 1999.

ASSOCIAÇÃO BRASILEIRA DE NORMAS TÉCNICAS. NBR 5674: Manutenção de edificações - Requisitos para o sistema de gestão de manutenção. Rio de Janeiro, 2012.

ASSOCIAÇÃO BRASILEIRA DE NORMAS TÉCNICAS. NBR 15.575: Norma de Desempenho e Durabilidade. Rio de Janeiro - RJ, 2012.

HELENE, P. R. L. Manual para reparo, reforço e proteção de estruturas de concreto. São Paulo: Pini, 1992.

Instituto Brasileiro de Avaliações e Perícias de Engenharia de São Paulo. Norma de Inspeção Predial. São Paulo, 2011. Disponível em: <http://www.ibape-sp.org.br/arquivos/norma_de_inspecao_predial.pdf>. Acesso em: 13 dezembro de 2019.

SOUZA, V. C.; RIPPER, T. Patologia, Recuperação e Reforço de Estruturas de Concreto - Pini - São Paulo - SP, 2009.

THOMAZ, E. Trincas em Edifícios: causas, prevenção e recuperação - Pini - São Paulo - SP, 2007. 